\title{
Finding Universals and Appreciating Differences: Philosophy and Method in Cross-Cultural Psychological Science
}

\author{
Raymond C. Hawkins, II \\ Fielding Graduate University; University of Texas at Austin, Austin, USA
}

\begin{abstract}
Despite the advances brought to psychology by multiculturalism and cultural diversity as a framework for social justice and improving human lives, there is a risk for what Bakan (1966) called "unmitigated agency" if multicultural and cultural diversity are reified as competencies that are then mandated in professional psychology training programs. A corrective alternative would be an integrative cross-cultural psychological science that would identify universals and appreciate differences across both individual personality and cultural contexts. Some of the principles for such an integrative applied cultural science are then generated, with examples, and a conceptual developmental model integrating biological factors (temperaments, endophenotypes), affect dynamics, attachment, and psychological type theory is offered.
\end{abstract}

Keywords: cross-cultural psychology, multicultural competencies, diversity, agency-communion, psychological type theory

\section{Introduction}

Multiculturalism and cultural diversity have become the zeitgeist for clinical and counseling psychology training and research (Arredondo et al., 1996; Bardone-Cone et al., 2016; Ellis \& Stam, 2015; Sue, Zane, Hall, \& Berger, 2009; Wadsworth et al., 2016a, 2016b). Recently the American Psychological Association reiterated its call for diversity training in its Multicultural Guidelines (APA, 2003) with a newer set of recommendations for clinical supervision of health service psychologists (APA, 2014). No doubt there is value in recognizing and remedying discrimination and injustice, consistent with APA's Ethical Principles (APA, 2002; 2010). However, shortcomings of multiculturalism and cultural diversity training have been noted in terms of equivocal evidence that training in multicultural competencies either improves clinical outcomes (e.g., Griner \& Smith, 2006; Huey, Tilley, Jones, \& Smith, 2014; Kirmayer, 2012; Patterson, 2004; Weinrach \& Thomas, 2002; Worthington, Soth-McNett, \& Moreno, 2007) or increases social justice (Vera \& Speight, 2003). Patterson (2004) has also criticized multicultural counseling competencies on philosophical grounds, namely that counseling is based on therapists' skill acquisition rather than on fostering healing relationships with clients, and stating that "client (cultural) differences are more important than client similarities" in terms of treatment selection (p. 68). Multiculturalism seeks to replace the "melting pot" metaphor with that of the "salad bowl" (D'Innocenzo \& Sirefman, 1992).

Does multiculturalism's "salad bowl" promotion of cultural diversity and multicultural competencies in

Raymond C. Hawkins, II, Ph.D., Core Faculty Member, Fielding Graduate University; Clinical Assistant Professor, Psychology Dept., University of Texas at Austin, email: rhawkins@utexas.edu. 
professional psychology training and research promote clinical science findings and tangible social justice benefits? Or does multiculturalism's disavowal of universal dimensions or parameters on which to compare and contrast cultural groups constitute a "word salad" that lacks coherence? The purpose of this brief essay is to consider these admittedly rhetorical questions within the contexts of history and systems of scientific psychology and philosophy, particularly as these pertain to personality and life contexts. This emphasis on the multicultural perspective may be seen as a Hegelian dialectical process that one might utilize in terms of philosophy of science and the politics of professional practice.

In the eugenics movement of the late 19th and early 20th centuries, certain cultural groups or perspectives were privileged, namely those of White Northern European males, and this special status claim was based upon presumed hereditary characteristics. It is important to note that the then new science of psychology, particularly the individual differences perspective, was misused in this eugenics argument. Interestingly, around the same time occurred the "Volkerpsychologie" ("folk psychology") of Wundt (1921 [1900], as cited in Ellis \& Stam, 2016) that emphasized the salience of nationalistic cultural characteristics. This, too, became an anathema, associated in popular culture with fascism and Hitler's Third Reich. However, in a sense, today cultural aggregates including nations, creeds, and religions are macro-processes that affect the individual within the domain of psychology: therefore, one may argue that these aggregates should be part of a cross-cultural psychological science, just like gender, race, ethnicity, class, sexual orientation, etc., and thus subject to research study and ethical analysis.

To understand the sociopolitical context for multiculturalism and its alternatives, there are a number of perspectives to consider that cut across social science disciplines, subsuming psychology, sociology, anthropology, economics, and political science. One can again see this process in terms of Hegel's formulation as "thesis - antithesis - synthesis" (Hegel, 1812), in that the new multicultural perspective seems to be aimed at rebalancing and privileging a view of diversity that is pluralistic, but it may risk imposing this view without sufficient justification and thus in an authoritarian manner.

\section{Balancing Agency and Communion}

Let us consider the basis of this risk for authoritarianism in multiculturalism. One perspective on this issue may be found in the philosophical view of David Bakan (1966), as expressed in his book, The Duality of Human Existence. In this book Bakan referred to the principles of agency and communion. Agentic traits, which now have largely been subsumed within Bandura's (1986) social-cognitive theory, involve self-efficacy attributions, and yet these can also be seen as a "will for power" within a more traditional philosophical context such as that of Nietzsche (1968). In contrast, the traits involving communion are more assimilative, accepting, and "feminine" (in the sense of the psychological attribute theory of Spence and Helmreich, 1978), as opposed to the "masculine" agentic characteristics. The interesting aspect of Bakan's (1966) theory is that "unmitigated agency" is destructive, and "unmitigated communion" can be seen as likewise destructive to the extent that individuals become passive and, in an almost evolutionary sense, do not propagate either biologically or culturally.

One could argue that the eugenics movement, privileging as it did the Northern European, White (particularly male) cultural voice, was unmitigated agency, a socio-political process that was essentially institutional racism (and sexism). In the 21 st century, there may be a risk that multicultural psychology/cultural diversity could be imposed through regulatory guidelines (e.g., those of the American Psychological Association) in such a way that would also constitute unmitigated agency if the emphasis placed upon 
multiculturalism and diversity extends beyond appreciating differences (as in a balance of agency and communion) to attacking the search for cross-cultural universals.

The proponents of multicultural psychology deserve credit for counteracting a pernicious tendency of psychologist researchers and practitioners to minimize the importance of cultural differences, or being (so-to-speak) "color blind" or "culture blind". A helpful metaphor for the mitigation or balancing of agency and communion is that of the "cultural traveler" who appreciates diversity in context, as a participant-observer who adopts an "emic" perspective rather than a more detached "etic" viewpoint. The "etic" or objective view, while being necessary for science, also runs the risk of prejudice, racism, and authoritarian judgments (i.e., unmitigated agency). Cheung (2012) has wisely recommended an integrated etic-emic approach to cross-cultural psychology research. The intersection of cultural group identities, and, as we shall see, including individual personality types needs to carefully to be considered and incorporated into such an integrative model.

So, what can we do to create a cross-cultural science that balances agency and communion? Cross-cultural psychology has a long history (e.g., Lonner, 2015), but the search for universals, called the "generalist" approach, has been rightly criticized by advocates of multicultural research (e.g., Hall, Yip, \& Zarate, 2016). Indeed, cross-cultural researchers who are generalists tend to use quantitative statistics and publish their findings in the Journal of Cross-Cultural Psychology; in contrast, multicultural researchers tend to use qualitative or mixed-methods designs and publish their studies in culture and psychology (Ellis \& Stam, 2015). We need to remember these historical trends. We also need to maintain dialogue, as theorists and as practitioners, rather than politically impose certain requirements on the curriculum for training clinical psychologists and scientists. A cross-cultural psychological science probably will need to take the useful findings that are coming from this particular multicultural diversity "zeitgeist", synthesize them with a critical deconstructivist psychology in the Hegelian sense, and then study and re-authorize these products, considering also alternative formulations (e.g., "cultural humility" and "cultural safety" as summarized by Kirmayer, 2012).

\section{Research Design Implications}

Such a synthesis and re-authorization could help to answer questions about the mediating and moderating effects of cultural contexts, broadly defined, in cross-cultural psychology. In psychology and research design race and ethnicity, in particular, have traditionally been treated as control variables for looking at effects of other independent variables. Now for cultural diversity studies, if indeed quantitative research designs are used at all (as grounded theory and other qualitative methods are more in vogue), these cultural influences should be considered as independent variables, as mediators and moderators, and also as dependent variables. Probably the study of cultural contexts should be studied within some mixed method fusion of quantitative and qualitative methods that allow for non-linear dynamical changes to be captured. In terms of causal mechanisms, temperament match/mismatch, and gene-environmental correlations and interactions, as seen in developmental psychopathology investigations of Avshalom Caspi (e.g., Caspi et al., 2003) and Michael Rutter (2007), need to be emphasized. In a sense, culture does actually constitute an integrative framework within which particular gene pools and environments (both biological and rearing environments) are seen as the complex interplay that results. If this complex "dance" of nature and nurture could be appreciated in its richness within cultural contexts (e.g., Sameroff, 2010), rather than politicized, then much could be learned and much progress could be made as a cross-cultural psychological science. Just as in medicine, the contribution of diversity of racial/ethnic background to wellness and disease-management and the role of epigenesis are now being studied and 
appreciated. We have a long way to go to get to such a cross-cultural psychological science, however. Nonetheless, this seems to be the promise.

\section{Cultural Rituals, Traditions, and Routines}

Another aspect that seems to cut across the disciplinary lines is once again to appreciate the role of cultural rituals, traditions, and daily routines. These environmental mechanisms channel social experience, protect/buffer the individual child or adult from risks, and maintain cultural differences. If we examine the subtle interaction between temperament and such socio-cultural rituals and routines, we should be able to create some of the boundaries and emphases of a new cross-cultural psychological science, which would be both empirical and hermeneutic, in that data would be gathered for discussion and innovation in the development of "person in culture" theories. A science can be created which is "open" and flexible, rather than closed and rigid, a science of inquiry, a science of dialogue, that is interdisciplinary and methodologically diverse. In a sense what is called for in this proposal is the deconstruction of cultural diversity and multiculturalism as an historical phenomenon that has become a force or mandate that is politicized and therefore has created dissension, and its reconstruction as a differentiated, yet integrated set of complex, contextual processes with emergent properties, that is to say, a new cross-cultural science paradigm. Such a reconstruction would open up new lines of research and theory development, and new dialogues that would search for uniformities, principles, and perspectives, while still appreciating differences, culturally as well as in terms of more basic biological and psychological processes.

\section{Personality/Psychological Type as a Bridge for a Cross-Cultural Science}

One way to promote a cross-cultural psychological science is to develop scalable constructs that can be applied to persons, groups, cultures, and values. For example, consider the Jungian personality "psychological type" metatheory underlying the Myers-Briggs Type Indicator (MBTI) (Myers, 1980) ${ }^{1}$. The values explicitly espoused in the MBTI involve increasing the conscious awareness and appreciation of psychological type differences (McCaulley, 2000). The MBTI is based on certain assumptions about the activity of people, who, within the parlance of dynamical systems and complexity theory, may be seen as acting as active self-organizing individual agents by manifesting combinations of the attitudes (introversion or extraversion) and functions (sensation, intuition, thinking, or feeling) into one of the MBTI "16 types" (Myers et al., 1998). These various "types" can then interact with one another, within a given ecological niche with a particular history of prior interactions and rituals, to create or enhance many of the cultural variations that are an overlay to evolutionary psychology processes discussed in contemporary theories of personality and social psychology, as well as in newer multicultural psychology formulations. This approach bears some similarity to Berry's (2004) "ecocultural" model. In contrast, The Five-Factor Model (e.g., NEO-PI, McRae \& Costa, 2010) is trait based and thus less amenable to characterizing the personalities of the individuals interacting within and between cultural groups.

What are some of these key assumptions that the MBTI embodies? First, as was just stated, the MBTI appreciates difference among people's personality styles and capacities. Second, the MBTI finds diversity and complexity within the Jungian individuation process, called type development, i.e., positing an active organism

\footnotetext{
${ }^{1}$ The MBTI has been found to be a reliable and valid measure of normal personality (Myers et al., 1998) that has shown utility in counseling (McCaulley, 2000) and cross-cultural applications (Kirby, Kendall, \& Barger, 2007; Schubhut \& Thompson, 2009).
} 
in which these tendencies of personality (the attitudes and functions) become manifest. Third, individual type dynamics and type development make possible a social psychological dynamic in which individuals manifesting different MBTI types interact vigorously and purposively, as in the "Game of Life" or "Second Life" in the form of virtual worlds, and can create many different interpersonal scenarios. Paul Ekman's (Ekman \& Friesen, 1975) research adds an interesting notion of "display rules" (Matsumoto, 1990) which may explain the apparent paradox that, despite the fact that different nationalities have distinctively different "personalities" (i.e., cultural personality stereotyping), the distribution of individual self-reported MBTI types shown in "type tables" (i.e., the frequencies of the 16 types) reveals notable consistency across these nationalities and cultures (Schubhut \& Thompson, 2009). People express more, or less, of their individual type and temperament characteristics according to the "display rules" for their culture. For example, in cultures that are more extraverted, such as the United States, individuals preferring introversion will still display more extraverted behaviors in culturally typical interactions. Individuals may publically espouse their individual psychological type, but still the cultural variations become obvious to those who are interacting with them (Allen, 2001; Kirby, Kendall, \& Barger, 2007). Cultural stereotypes may derive from Jungian "cultural complexes" (Singer \& Kimbles, 2004) that reflect a cultural history of traumas or triumphs. However, conscious awareness of both these inherent individual personality differences and the culturally proscribed social behaviors can give rise to dialogue with a spirit of inquiry to discover some of the uniformities of the processes by which these individual differences related to type and temperament are filtered through cultural expectations and rituals and then become manifest.

Within the Jungian metatheory underlying the MBTI there is a consideration of determinants outside of awareness, so to speak from the "collective unconscious" (e.g., personal and cultural complexes), as well as from personal historical and familial factors (i.e., a kind of alchemical "melting pot" for the "Whole"). Within personality science we now of course realize that there are certain psychological markers, the so-called endophenotypes, which are very closely related to underlying neurotransmitters and neural circuits, so to speak, the "operating system" of the human Psyche. To a certain extent these operating system characteristics developmentally become manifested as temperaments and then as psychological types, and these can further be assembled into larger cultural units. From this example of psychological type theory we have the basis for an integrative, cross-cultural psychological science that to a certain extent breaks down some of the barriers between scholarly disciplines. The whole process of social psychology, of social stigmatization, of privilege, and of power that cuts across disciplinary lines constitutes a cultural science project that should take advantage of these interdisciplinary ideas and "bridge" constructs, becoming a more transformational, emergent science in that sense.

\section{Affect Dynamics, Scenes, and Scripts}

Another example of building such an integrative bridge may be seen in the affect dynamics, scene and script theory of Sylvan Tomkins (Tomkins, 2008a; 2008b), particularly as elaborated by Magai and Haviland-Jones (2002). Haviland-Jones, like Ekman, was a student of Tomkins. Tomkins' theory of motivation and personality emphasizes the primacy of emotions and how these emotions and their expression or display emerge in the context of interpersonal scenes and scripts, which ultimately produce the individual's unique "ideoaffective" system structure (Magai \& Haviland-Jones, 2002). Neither Tomkins nor his students developed the cultural bridge for affect dynamics and script theory, as these basic emotions and their facial display were 
seen as either universal evolutionary adaptations (but consider the display rules, Ekman \& Friesen, 1975) or uniquely individual dynamical systems (Magai \& Haviland-Jones, 2002).

How can cultural diversity be built from the bottom up? Here is one possible conceptual model. The interplay of neurobiological temperaments/endophenotypes of the infant/child and parent(s) may bias affective dynamics in the primary attachment relationships (Tomkins' nuclear or generative scenes) and activate emergent attractors and repellors for particular emotions. Note that in this sense psychological type may be seen as a form or pattern of a developing identity script channelized by ideoaffective dynamic systems ${ }^{2}$. But in turn early psychological type development and interpersonal type dynamics (Hawkins, 1993; Hawkins \& Meier, 2015) may shape the final ideoaffective system structure in the growing child. Cultural display rules (Ekman \& Friesen, 1975) may then create cultural differences not only in the facial expressions of the basic emotions but also in the modulation of behaviors congruent with a particular individual psychological type. By adolescence and adulthood awareness of one's preferred psychological type, the distinctions between it and the other types, and especially the appreciation of these type related differences through type-informed communication skills training and psychotherapy may release what Tomkins (1978) called "backed-up" affects, rebalance overly one-sided type development and heal cultural stereotypes and prejudices.

\section{Psychological Type as a Fractal Construct}

One final elaboration of Jungian type theory as a framework for deconstructing cultural diversity and reconstructing a cross-cultural psychological science is that this theoretical framework explicitly assumes that the personality attributes (the attitudes and functions) can be used equivalently across levels of analysis. Thus, the MBTI "16 types" can be applied to individuals, to organizations, to environments that are specified (e.g., Salter's Environmental Type Assessment), and to larger social units such as groups and cultures (Hawkins \& Meier, 2015). Having the possibility of self-similarity across scales (i.e., a "fractal" nature) facilitates dialogue about how these different components are assembled. Where there are uniformities across levels or distinctions, it is important to be able to appreciate and study these distinctions from both an "emic" perspective, the perspective of those participating in a particular culture or level of analysis, and from the "etic" perspective, from the observer standing apart and creating categories that are universal or will facilitate comparison. There is also the risk from the "etic" perspective, though, of authoritarian oversimplifications and judgments ("unmitigated agency") that are stereotypes that may become politicized in culture wars, manifesting as prejudice and actual discrimination (e.g., the moral debate about assisted suicide, Hawkins, in press). The MBTI application of Jungian psychological type theory was the product of the wisdom and values of Isabel Briggs Myers, who developed the MBTI as her personal mission to facilitate a constructive use of personality differences in the world at the time that Hitler and fascism were creating chaos (Myers, 1980). The way that the MBTI type dimensions were laid out on the report form, was that the polarities were arranged as "Extravert" (E), "Sensation" (S), "Thinking" (T), and "Judging" (J) on the right side, and on the left side were the poles of "Introversion" (I), "Intuition" (N), "Feeling" (F), and "Perception" (P). This layout was not intended to privilege either set of poles over the other; however, consistent with Jung's psychology, if the conscious

\footnotetext{
${ }^{2}$ Although Magai and Haviland-Jones (2002) posit that each individual's ideoaffective structure is unique, the MBTI "16 types" may be seen as patterns of ideoaffective system structures that some people share, while Tomkins' (2008b) nine primary emotions or affects (i.e., interest-excitement, enjoyment-joy, surprise-startle, distress-anguish, fear-terror, shame-humiliation, contempt-disgust, anger-rage and dissmell) may be regarded as universal.
} 
orientation were to become too one-sided, then for "ESTJ" we would have "unmitigated agency" and for "INFP" there would be "unmitigated communion". This distinction is a bit oversimplified, but it makes a general and important point: because psychological type is not so homogeneous and one-sided, Jung's theory involves the balancing or reconciliation of oppositions (recall the Hegelian dialectic mentioned at the outset of this essay). The notion is that for an ESTJ experiencing good type development and individuation, the "INFP" aspect (specifically the inferior function, "introverted feeling") would be integrated such that the agentic dominant function ("extraverted thinking") would be mitigated by the communal awareness (i.e., balanced with more conscious awareness and skillful use of "introverted feeling"), and vice versa for the INFP type integrating "extraverted thinking", and thereby balancing unmitigated communion tendencies with agency.

\section{Conclusion}

Multiculturalism and cultural diversity constitute a zeitgeist that has enhanced the ethics of research and practice in clinical and counseling psychology. However, the evidence is limited that training of multicultural competencies as skill-sets makes a significant contribution to improving treatment outcome and/or social justice. Furthermore, there are philosophical and methodological limitations to this diversity zeitgeist (i.e., the focus on competencies and on differences rather than commonalities, and the lack of universal dimensions or parameters on which to compare and contrast cultural groups). Whether or not the examples of an integrative contextual model and methods presented in this essay will facilitate a reconstruction of cultural diversity into a new cross-cultural psychological science remains to be seen, but the "melting pot" metaphor may still have a certain heuristic value ${ }^{3}$. As Kurt Lewin (1951) said, "Nothing is so practical as a good theory". In elucidating the synergy between theory and method, Greenwald (2012) has recently said, "There is nothing so theoretical as a good method" (p. 99).

\section{References}

Allen, J. (2001). Different similar: How type is expressed across cultures. Bulletin of Psychological Type, 24(4), 35-36.

American Psychological Association $(2002,2010)$. Ethical principles of psychologists and code of conduct. Retrieved from http://www.apa.org/ethics/code/principles.pdf.

American Psychological Association. (2003). Guidelines on multicultural education, training, research, practice, and organizational change for psychologists. American Psychologist, 58, 377-402.

American Psychological Association. (2014). Guidelines for clinical supervision in health service psychology. Retrieved from https://apa.org/about/policy/guidelines-supervision.pdf

Arredondo, P., Toporek, M. S., Brown, S., Jones, J., Locke, D. C., Sanchez, J., \& Stadler, H. (1996). Operationalization of the multicultural counseling competencies. Alexandria, VA: AMCD.

Bakan, D. (1966). The duality of human existence: Isolation and communion in western man. Boston, MA: Beacon Press.

Bandura, A. (1986). Social foundations of thought and action: A social cognitive theory. Englewood Cliffs, NJ: Prentice-Hall.

Bardone-Cone, A. M., Calhoun, C. D., Fischer, M. S., ... \& Prinstein, M. J. (2016). Development and implementation of a diversity training sequence in a clinical psychology doctoral program. The Behavior Therapist, 39(3), 65-75.

Berry, J. W. (2004). An ecocultural perspective on the development of competence. In R. J. Sternberg, \& E. Grigorenko (Eds.), Culture and competence (pp. 3-22). Washington, DC: American Psychological Association.

\footnotetext{
${ }^{3}$ Kegan (1994) has described a trans-system subject-object level of postmodern consciousness in which cultural conflicts between parties may be viewed as part of a larger whole: "the conflictual relationship creates the parties; the parties do not create the relationship" (p. 320). Conflict resolution from this perspective can perhaps be seen as analogous to the Jungian individuation process: "the Palestinian discovers her own inner Israeli-ness, the rich man discovers his poverty, the woman discovers the man inside her" (p. 321). Thus it is not possible to separate the interacting persons from the cultural context. The larger whole may be seen as a "melting pot" where new meanings and behaviors can be distilled.
} 
Caspi, A., Sugden, K., Moffitt, T. E., ... Poulton, R. (2003). Influence of life stress on depression: Moderation by a polymorphism in the 5-HTT gene. Science, 301, 386-389.

Cheung, F. M. (2012). Mainstreaming culture in psychology. American Psychologist, 67(8), 721-730.

D’Innocenzo, M., \& Sirefman, J. P. (1992). Immigration and ethnicity: American society- "melting pot" or "salad bowl". Westport, CT: Greenwood.

Ekman, P., \& Friesen, W. V. (1975). Unmasking the face. Englewood Cliffs, NJ: Prentice-Hall.

Ellis, B. D., \& Stam, H. J. (2015). Crisis? What Crisis?: Cross-cultural psychology's appropriation of cultural psychology. Culture \& Psychology, 21(3), 293-317.

Greenwald, A. G. (2012). There is nothing so theoretical as a good method. Psychological Science, 7(2), 99-108.

Griner, D., \& Smith, T. B. (2006). Culturally adapted mental health interventions: A meta-analytic review. Psychotherapy: Theory, Research, Practice, Training, 43(4), 531-548.

Hall, G. C. N., Yip, T., \& Zarate, M. A. (2016). On becoming multicultural in a monocultural research world: A conceptual approach to studying ethnocultural diversity. American Psychologist, 71(1), 40-51.

Hawkins, R. C. II (1993, July). Psychopathology emerging within a relational field: Insights from Jungian theory, type development, and cognitive science. Proceedings of the Tenth Biennial International Conference of the Association for Psychological Type, Newport Beach, CA.

Hawkins, R. C. II (in press). Agency and communion in end-of-life decision-making. Illness, Crisis, \& Loss, 25(2).

Hawkins, R. C. II, \& Meier, S. T. (2015). Psychotherapeutic theories of change and measurement: An integrative model. Journal of Unified Psychotherapy and Clinical Science, 3(1), 80-119.

Hegel, G. W. F. (1812). The science of logic. Retrieved from http://www.hegel.net/en/pdf/Hegel-Scilogic.pdf

Huey, S. J., Jr., Tilley, J. L., Jones, E. O., \& Smith, C. A. (2014). The contribution of cultural competence to evidence-based care for ethnically based populations. Annual Review of Clinical Psychology, 10, 305-338.

Kegan, R. (1994). In over our heads: The mental demands of modern life. Cambridge, MA: Harvard University Press.

Kirby, L., Kendall, E., \& Barger, N. J. (2007). Type and culture: Using the MBTI instrument in international applications. Palo Alto, C.A.: Consulting Psychologists Press.

Kirmayer, L. J. (2012). Rethinking cultural competence. Transcultural Psychiatry, 49(2), 149-164.

Lewin, K. (1951). Field theory in social science: Selected theoretical papers. (D. Cartwright, Ed.). New York, N.Y.: Harper \& Row.

Lonner, W. J. (2015). Half a century of cross-cultural psychology: A grateful coda. American Psychologist, 70(8), 804-814.

Magai, C., \& Haviland-Jones, J. (2002). The hidden genius of emotion: Lifespan transformations of personality. Cambridge, UK: Cambridge University Press.

Matsumoto, D. (1990). Cultural similarities and differences in display rules. Motivation and Emotion, 14(3), 195-214.

McCaulley, M. H. (2000). The Myers-Briggs Type Indicator in counseling. In E. Watson, Jr., \& V. L. Campbell (Eds.), Testing in counseling practice (pp. 110-173). New York, NY: Lawrence Erlbaum.

McCrae, R. R., \& Costa, P. T. (2010). NEO Inventories professional manual. Lutz, FL.: PAR.

Myers, I. B. (1980). Gifts differing. Palo Alto, CA: Consulting Psychologists Press.

Myers, I. B., McCaulley, M. H., Quenk, N., \& Hammer, A. L. (1998). MBTI ${ }^{\odot}$ manual. Palo Alto, CA: Consulting Psychologists Press.

Nietzsche, F. (1968). The will to power (Translated into English by W. Kaufman \& R. J. Hollingdale; Editor, W. Kaufman). New York, NY: Random House.

Patterson, C. H. (2004). Do we need multicultural counseling competencies? Journal of Mental Health Counseling, 26(1), 67-73.

Rutter, M. (2007). Genes and behavior: Nature-nurture interplay explained. New York, NY: Wiley.

Sameroff, A. (2010). A unified theory of development: A dialectic integration of nature and nurture. Child Development, 81, 6-22.

Schubhut, N. A., \& Thompson, R. C. (2009). MBTI ${ }^{\odot}$ type tables international. Palo Alto, CA: Consulting Psychologists Press.

Singer, T., \& Kimbles, S. L. (Eds.) (2004). The cultural complex: Contemporary Jungian perspectives on psyche and society. New York, NY: Brunner-Routledge.

Spence, J. P., \& Helmreich, R. L. (1978). Masculinity and femininity. Austin, TX: University of Texas Press.

Sue, S., Zane, N., Hall, G. C. N., \& Berger, L. K. (2009). The case for cultural competency in psychotherapeutic interventions. Annual Review in Psychology, 60, 525-548.

Tomkins, S. S. (1978). Script theory: Differential magnification of affects. In H. E. Howe, Jr. (Ed.), Nebraska Symposium on Motivation, 1978. Lincoln, NB: University of Nebraska Press. 
Tomkins, S. S. (2008a). Affect, imagery, consciousness: The complete edition (Volume I and Volume II). New York, NY: Springer.

Tomkins, S. S. (2008b). Affect, imagery, consciousness: The complete edition (Volume III and Volume IV). New York, NY: Springer.

Vera, E. M., \& Speight, S. L. (2003). Multicultural competence, social justice, and counseling psychology: Expanding our roles. The Counseling Psychologist, 31(3), 253-272.

Wadsworth, L. P., Morgan, L. P., Hayes-Skelton, S. A., Roemer, L., \& Suyemoto, K. L. (2016a). Ways to boost your research rigor through increasing your cultural competence (Part 1 of 2). The Behavior Therapist, 39(3), 76-82.

Wadsworth, L. P., Morgan, L. P., Hayes-Skelton, S. A., Roemer, L., \& Suyemoto, K. L. (2016b). Ways to boost your research rigor through increasing your cultural competence (Part 2 of 2). The Behavior Therapist, 39(3), 90-92..

Weinrach, S. G., \& Thomas, K. R. (2002). A critical analysis of the multicultural counseling competencies: Implications for the practice of mental health counseling. Journal of Mental Health Counseling, 24(1), 20-35.

Worthington, R. L., Soth-McNett, A. M., \& Moreno, M. V. (2007). Multicultural counseling competencies: A 20 year content analysis. Journal of Counseling Psychology, 54(4), 351-361.

Wundt, W. (1921[1900]). Volkerpsychologie: Eine Untersuchung der Entwicklungsgesetze von Sprache, Mythos, und Sitte (Volkerpsychologie: An examination of the developmental laws of language, myth, and custom) (Vol. 1), Die Sprache (Language). Stuttgart: Alfred Kroner Verlag. 